\title{
Sor Juana y la cosmología barroca: "Primero sueño"'
}

\author{
Roberto GONZÁLEZ ECHEVARRÍA \\ Yale University \\ roberto.echevarria@yale.edu
}

\begin{abstract}
RESUMEN
El texto que sigue aprovecha el trabajo que he publicado sobre el barroco y, en especial, mi ensayo "Lírica colonial," que aparece en la Historia de la literatura hispanoamericana, que Gredos publicó en el 2006, y que había aparecido en su versión original inglesa en la Cambridge History of Latin American Literature, de 1996. También retomo algunas de las ideas de Celestina's Brood: Continuities of the Baroque in Spanish and Latin American Literature, que se publicó en España como La prole de Celestina. Pero aquí aspiro a ir más lejos al concentrarme en un solo poema de Sor Juana, "Primero sueño", y utilizar ideas que he ido desarrollando en los últimos diez o quince años. Las más recientes forman parte de un libro en marcha sobre el infinito y la improvisación del que ya han aparecido algunos adelantos sobre Cervantes y Calderón. Hay otro sobre Lope en camino.
\end{abstract}

Palabras clave: "Primero sueño", barroco, cosmología.

\section{Sor Juana and the baroque cosmology: "Primero sueño"}

\begin{abstract}
The text that continues takes advantage of the work that I have published on the baroque and, especially, my test "Lírica colonial" that appears in the Historia de la literatura hispanoamericana, which Gredos published in 2006, and that had appeared in his original English version in the Cambridge History of Latin American Literature, of 1996. Also I take again some of Celestina's Brood's ideas: Continuities of the Baroque in Spanish and Latin American Literature, which was published in Spain as La prole de Celestina. But here I aspire to be going to center beyond in a alone Sor Juana's poem, "Primero sueño", and to use ideas that I have been developing in the last ten or fifteen years. The most recent form a part of a book in march on the infinite and the improvisation of the fact that already some advances have appeared on Cervantes and Calderón. There is other one on Lope in way.
\end{abstract}

Key words: "Primero sueño", baroque, cosmology.

1 El siguiente trabajo fue leído en la Universidad Complutense de Madrid, el 28 de mayo del 2014, en el contexto del seminario "Escrituras Virreinales: variedad discursiva en las Indias". 
La poesía de Sor Juana Inés de la Cruz culmina el proceso de renovación poética en lengua castellana que empieza con la publicación de la poesía de Garcilaso de la Vega en 1543 y que alcanza cimas inigualadas en las obras de San Juan de la Cruz, Fray Luis de León, Lope de Vega, Francisco de Quevedo y Pedro Calderón de la Barca. Su obra es una síntesis a la vez que un balance a la altura de todo lo precedente. Pero fue además una conclusión. Tendría que pasar mucho tiempo antes de que surgiera, en nuestra lengua, un poeta de su calidad -pienso que hasta Rubén Darío, y más adelante la generación del 27-. La evolución poética que termina con Sor Juana abarca dos períodos reconocibles, el Renacimiento y el Barroco, siendo el segundo una transformación sustancial, pero no absoluta y deliberada del primero; poetas como Góngora y Quevedo todavía pensaban que escribían en el estilo de Garcilaso y Calderón se consideraba discípulo de Lope.

Pero el cambio de uno a otro estilo es indiscutible y, aunque no fueran explícitas o radicales las innovaciones realizadas fueron profundas porque involucraban los componentes fundamentales del discurso literario renacentista: aparte del petrarquismo, y la estela que deja la retórica del amor cortés, la mitología clásica y la cosmología medieval, que había culminado con el renovado interés por Tolomeo y su sistema, el más abarcador para concebir y representar el universo y su funcionamiento en la época. Tolomeo había sido parte del rescate del legado clásico propio del humanismo renacentista, irónicamente ocurrido justo en el momento en que Copérnico y sus seguidores echaban abajo el andamiaje material de sus teorías. El descubrimiento de América y la mera existencia de un vasto Mundo Nuevo ponían en jaque la obra del sabio helenista y sacudían los cimientos teológicos a los que servían de apoyo ${ }^{2}$. Todo esto está en juego en la transición de la poesía renacentista a la barroca, cuando hace crisis, en Sor Juana de manera muy especial, como espero poder demostrar en lo que sigue, en su "Primero sueño".

Mis hábitos pedagógicos me impelen a hacer una breve descripción del poema antes de pasar a mi comentario. Sé que ninguna exposición de ese tipo es inocente, sino que tiende a inclinar el texto descrito en favor del análisis crítico que sigue. Pero también sé que "Primero sueño" no es el tipo de poema que nos aprendemos de memoria en la escuela, y que aun los que lo hayan leído recientemente agradecerán un estímulo mnemónico. "Primero sueño" es un poema difícil.

Para empezar, Sor Juana no le dio el título "Primero sueño" al poema, sino sus editores, ella lo llamó "Sueño". Es un largo poema, de 975 versos -el equivalente de un acto de comedia del Siglo de Oro- en que la voz narrativa, que habla en primera persona, narra desde el anochecer hasta el amanecer, y el sueño que experimenta un individuo que no es necesariamente ella hasta el último verso. En su

\footnotetext{
${ }^{2}$ Ver el utilísimo libro de García Santo Tomás.
} 
prosificación del poema, que es en realidad una glosa algo engañosa, Alfonso Méndez Plancarte, hace la voz poética protagonista de "Primero sueño", pero yo sostengo que Sor Juana establece distancia entre ésta y el individuo cuyo sueño se relata. Los versos, de siete y once sílabas, que están organizados en silvas de variable longitud, son de una densidad gongorina por sus múltiples hipérbatos, retruécanos, metáforas sobre metáforas, cultismos, y algún que otro neologismo. En el sueño se da cuenta del ansia de conocimiento del alma que pretende alcanzar la Causa Primera, Dios, para entender el universo, en particular al ser humano mismo. El cuerpo de éste se describe en detalles minuciosos a medida que se va quedando dormido, siguiendo la terminología anatómica de la época -humores, calor, húmedo radical- y luego su alma, también utilizando el léxico al uso, de origen escolástico, potencias, facultades, etc. También se describe el universo, tal y como éste se ofrece a la voz poética que se esfuerza por comprenderlo. Es un cuadro completo que abarca desde el sol, la luna y las estrellas hasta el mar, las montañas, los volcanes, y las criaturas que pueblan los cuatro elementos de que se compone la realidad, agua, fuego, tierra, y aire, ateniéndose también a la ciencia de origen aristotélico predominante todavía en el siglo XVII, con ecos de Ovidio. "Primero sueño" es un poema enciclopédico, resabio medieval típico del barroco. Cuando rompe el día el sujeto comienza a despertarse, lo cual se narra otra vez con pormenores sobre los cambios físicos y mentales, hasta el último verso, cuando la voz se identifica al decir "y yo despierta", un final sorpresivo porque hasta ahora no ha habido especificidad en cuanto a quien habla, y qué relación hay entre el durmiente y el origen de la ficción.

Este recuento del poema me obliga a mencionar una obsesión mía de los últimos años, el concepto crítico de, valga la palabra, conceit en inglés, del que no tenemos equivalente en español, pero que me parece un instrumento extremadamente útil para aproximarse a la poesía. Conceit, desde luego, está relacionado etimológicamente a concepto, y de ahí podemos pasar a establecer un vínculo con nuestro conceptismo, con el cual fácilmente se puede asociar la poesía de Sor Juana, "Primero sueño" en particular. En inglés conceit se ha visto en relación con los poetas metafísicos, y en la era moderna con T.S. Eliot. Se trata de una cadena de metáforas relacionadas por cualidades físicas o mentales, las físicas lo aproximan más al gongorismo nuestro, las mentales al conceptismo; a veces colinda con la alegoría. Pero para mí lo interesante del término es lo que tiene además de actuación, de performance, de presunción, de puesta en escena, de hacerse pasar por alguien o por algo, y me gustaría proponer que conceit sería algo así como la ficción englobante que posibilita el poema. En el caso de "Primero sueño" es precisamente el sueño dentro del cual acontece la acción.

Que yo sepa no hay poema filosófico semejante a "Primero sueño" en toda la poesía del Siglo de Oro. No debe sorprendernos que fuera Sor Juana quien lo escribiera porque la monja mexicana no fue sólo escritora, sino una intelectual en toda la regla. Es decir, Sor Juana estaba al tanto de las corrientes de pensamiento de 
su época tanto como de las literarias, e intervino en los debates sobre algunas de ellas, como es harto sabido y es patente en sus escritos en prosa, su "Respuesta a Sor Filotea de la Cruz" muy en particular. En sus "Ovillejos" y otros poemas Sor Juana también demuestra que está muy consciente del lugar que ella ocupa en la trayectoria de la poesía en lengua española, y también en otras lenguas, sobre todo la italiana. Por su celda, como ha detallado Octavio Paz en su indispensable libro, pasaban la mayoría de las figuras políticas, intelectuales y literarias del momento, con las que discutía y debatía asuntos de actualidad, y participó en ceremonias y festejos de la corte virreinal, con la que tuvo una relación estrecha y sostenida. Su participación en el teatro es muestra clara de su entrega a las actividades artísticas en el México que le tocó vivir, y su amistad con Carlos de Sigüenza y Góngora su familiaridad con las más avanzadas teorías cosmológicas y filosóficas de entonces. Sor Juana participaba, en vivo, por así decir, en la dinámica vida intelectual del Virreinato de la Nueva España, original y modelo de los virreinatos que seguirían en el futuro, por los que su fama se extendió también además de por la Península.

La postura filosófica de Sor Juana en "Primero sueño", en particular su vertiente cosmológica, también reflejaba su situación vital, algo que sospecho no se ha destacado bastante. Vivir en el Nuevo Mundo le daba a Sor Juana una perspectiva geográfica y hasta cósmica distinta de la de los poetas europeos renacentistas y barrocos. A la nostalgia de Roma propia de éstos, que era temporal, se sumaba en su caso una añoranza espacial. ("Buscas en Roma a Roma, ;oh peregrino!, /y en Roma misma a Roma no la hallas" -Quevedo-). Los europeos escribían desde su propio centro y en el lugar de los hechos, evocando el pasado ideal que era para ellos la Roma clásica. Sor Juana estaba separada de ésta no sólo por siglos, sino por el vasto Océano Atlántico, por meses de un penoso, y para ella impensable viaje. La suya era una separación concreta, objetiva, terrestre. También mediaba entre ella y Roma un pasado prehispánico que le era contemporáneo, no sólo en la abrumadora presencia indígena, sino en los imponentes monumentos del mundo azteca, que había sido derrotado, pero no borrado, y sobre el cual se erigía en híbrida síntesis la cultura virreinal. Las ruinas que Sor Juana observaba, que formaban parte de su vida diaria, no eran las del poema de Rodrigo Caro ("Estos, Fabio, ¡ay dolor! que ves ahora"), sino las del imperio de Moctezuma, cuya grandeza celebraba su amigo Sigüenza y Góngora en sus escritos y en sus aparatosos arcos triunfales, hoy estudiados con su acostumbrada erudición y sagacidad por mi querida colega y amiga Rolena Adorno. Había un pasado actual y sólido que se levantaba ante la monja al evocar la Roma imperial, y también el más remoto pero tal vez cercano Egipto, cuyas pirámides le recordarían las de México y le sugerirían un posible origen común de toda la humanidad.

Los monumentos aztecas, además, eran de dimensiones cósmicas, como para ser observados desde otros planetas, lo cual debe haber creado en Sor Juana una extraordinaria sensación del espacio terrenal y astral. Por muy enormes que fueran las catedrales erigidas por los españoles, a veces sobre ruinas aztecas, no podían 
compararse con las prehispánicas que poblaban su presente. Sólo las colosales pirámides egipcias, que figuran prominentemente en "Primero sueño", podían compararse con los monumentos aztecas. El sentido de la proporción de Sor Juana, y de su lugar en el espacio era distinto de los de los poetas europeos que la precedieron para quienes, en el mejor de los casos, sólo tenían como referente las grandiosas ruinas romanas, que no alcanzaban la inmensidad y altura de las mexicanas. Aún hoy, pasearse por el Zócalo en México produce una sensación casi de vértigo, y a mí me hace pensar que la Plaza de la Catedral de mi querida Habana es apenas un juguete en comparación.

La cosmología azteca, que se reflejaba en esos grandiosos monumentos, de la que Sor Juana sin duda estaba al tanto, entre otras vías por su amistad con Sigüenza y Góngora, tenía que hacerla sensible a la validez relativa de la prevalente en el pensamiento corriente de España y sus reinos de ultramar. Atentos observadores de la bóveda celeste, los habitantes del altiplano habían concebido un sistema cósmico, del que habían derivado su estimable calendario, que compitió con el católico en el establecimiento del transcurrir del tiempo en el virreinato, aunque tuvo a la postre que someterse a éste. La prodigiosa organización de tiempo y espacio visible en la arquitectura y diseños urbanos aztecas no podía menos que grabarse en la mente de la poeta, preocupada por todo lo referente al orden cósmico, estético, filosófico y social.

Tal vez fuera debido a ese abrumador panorama y concepto del espacio que la prevalente penumbra en "Primero sueño" borra paulatinamente la realidad para empezar a partir de la nada; de lo no existente o por lo menos lo no perceptible por los sentidos. O mejor, para empezar por las apariencias sólo alojadas en la memoria, como el sonido y ritmo de las palabras que habrían de componer su poema -ecos lingüísticos y poéticos que constituían su subconsciente literario-. Lo único concreto en estas apariencias acústicas y su expresión es el tiempo en que se manifiestan, que no podía ser abolido o negado, pero que en el sueño obedecía a sus propias reglas ${ }^{3}$. De ese depósito auditivo-temporal, de esa memoria poética, extraería Sor Juana la forma de "Primero sueño". Por su encuadre temporal, que abarca desde el caer la noche hasta el alba, desde el dormirse hasta el despertarse y el amanecer, "Primero sueño" es como una égloga al revés. La égloga transcurre desde la aurora hasta el crepúsculo; es un poema diurno. El uso de la silva, con su alternancia de versos de siete y once sílabas es una clara alusión a las églogas de Garcilaso y las Soledades de Góngora. Por contraste, "Primero sueño" sería entonces como una pastoril nocturna, algo conceptualmente imposible y por eso mismo significativo. Se persigue en la égloga la plenitud filosófica y estética de la pastoril; belleza, amor, e imágenes fundidos en un paisaje perfecto, paradisíaco. Pero en "Primero sueño" -donde lo erótico está ausente- se busca esa plenitud en la

\footnotetext{
${ }^{3}$ No tenía que nacer Freud para darse cuenta de esto.
} 
noche y en el sueño, no a la luz del día y del conocimiento consciente inspirado por la belleza visual que la naturaleza ofrece. Este contraste con la pastoril no puede ser casual en un poeta tan culto como Sor Juana. La pastoril acarreaba consigo todo el legado neoplatónico del arte y de la poesía renacentista; en español desde Garcilaso a Góngora-Soledades es un poema pastoril-. Sor Juana se distancia de esa herencia, tan poderosa en su tiempo, explotando una de las contradicciones generadoras en la base de la poesía bucólica: resaltar la belleza natural en creaciones que se basan no en una exaltación de los sentidos, sino en la capacidad de la mente para crear arquetipos interiores de belleza pura. Por supuesto, en Garcilaso, Fray Luis o Góngora las minucias de lo contingente y visible están camino a sumarse y sumirse en arquetipos de belleza. Sor Juana, por el contrario, explora la existencia de estos en la imaginación del poeta, es decir, en el sueño, que es su mundo.

En esto también el contraste de "Primero sueño" con la égloga es manifiesto y sugestivo. La égloga, y la pastoril en general, es una literatura de lo externo, del paisaje de la luz, del diálogo entre los pastores y los amantes -a veces el llamado canto amebeo-. Soledades es un poema de lo externo, de paisajes marinos y rurales, de opulentos ritos nupciales, de la belleza pura expresada en una lengua dilatada hasta el límite. No hay intimidad en "Primero sueño", como no la hay en Góngora. La voz poética maniobra sobre la línea divisoria entre lo externo y lo interno. Porque lo interno lo es literalmente; descrito en detalle con un vocabulario hecho de lugares comunes de la anatomía escolástica, es algo físico, no algo que se aloja en una interioridad anímica. Excepto que, a pesar de todo, esa voz habla -las pocas veces que lo hace- en primera persona; pero sólo para revelar un interior que es externo a ella, como si fuera la lámina de un tratado de medicina, un cuerpo que pertenece a otro, pero que la implica de todos modos por analogía. En este sentido, como en otros, Sor Juana abre un espacio intelectual y poético que esboza un tipo de conciencia que se me hace pre-romántica; en el romanticismo el yo se manifestará no sólo abiertamente sino haciendo de su presencia espectáculo. No ofrece la égloga invertida de Sor Juana un agreste paisaje como los de Wordsworth, impreso en lo más profundo del alma del poeta por el espíritu de la naturaleza, pero en cierto modo lo anuncia ${ }^{4}$. El universo de Sor Juana, incluso su yo, está sometido al discurso científico de su época: cuatro elementos, con sus características y criaturas propias, claramente divididos, regiones siderales nombradas según la nomenclatura al uso, un alma hecha de potencias y facultades. Se trata del discurso rutinario de la escolástica que gobierna el ambiente intelectual del Virreinato, sujeto a sus propias volutas silogísticas, su acopio de citas de autoridades pasadas de moda, su repertorio léxico divorciado tanto de la realidad material como de la realidad psíquica. La voz poética sólo puede asomarse a través de esa maraña verbal

${ }^{4}$ Sor Juana, por el temple cósmico de su poesía me evoca más a Blake, pero sobre todo al Yeats de "A Vision". 
en el último verso, como alguien que saca desesperadamente la cabeza del agua para no ahogarse.

Hay una curiosa inversión en el trasfondo filosófico del poema. Basada en Aristóteles y codificada por Santo Tomás, la escolástica pretendió ser en el principio una filosofía de lo sensible, de lo real, en contraste con el idealismo típico de Platón y el neoplatonismo. Pero a medida que avanza la historia, sobre todo en España y sus dependencias, la escolástica se fue convirtiendo en un código autónomo, desvinculado de lo real, un idealismo lógico-verbal que se hizo independiente en su propio funcionamiento guiado por reglas intrínsecas. En la eterna disputa entre Platón y Aristóteles, este último cambia de lugar con su maestro. No fue lo anterior lo único que produjo la filosofía escolástica, también surgió en su seno una figura de la importancia y alcance de Francisco Suárez, que tuvo gran impacto en escritores como Calderón.

En el poema de Sor Juana la búsqueda de la verdad, del conocimiento, en el sueño es una inversión de la inversión, por así decir, una inversión duplicada o al cuadrado. Si la vida es sueño (para recordar a Calderón), entonces lo que se analiza en el poema de Sor Juana es el sueño, que vendría a ser la verdad contrapuesta de la vida; pero el despertar al final desvanece el sueño, que es después de todo otro engaño. Se trata, por lo tanto de un desengaño en que el engaño, típicamente, se revela como tal. No es un despertar a la vida eterna, que sería la vida verdadera en términos cristianos. El despertar de Sor Juana es a lo circunstancial y real de su vida en particular, por eso el sorpresivo énfasis en el género femenino del último verso, "Y yo despierta," y del implícito presente de indicativo: "Yo estoy despierta." Aparte de lo que pueda tener de feminismo incipiente, sirve esa identificación tan precisa para hacer hincapié en que el despertar es a la vida real y suya propia, que es la de una mujer de carne y hueso, no la de un ente abstracto que regresa del sueño a referir verdades descubiertas en el transcurso de éste. También menciona Sor Juana el lugar común, que se remite a la antigüedad clásica, que equipara el sueño a la muerte. El sueño vendría a ser una representación de la muerte, su anticipo, o hasta su ensayo. La comparación es explícita en "Primero sueño," lo cual le da un tinte todavía más barroco. La historia que cuenta el poema es como haber visitado la muerte y regresado de ella a la vida. Más que a Góngora, Sor Juana seguía a Calderón, abiertamente en su teatro, pero muy en especial en la forma en que el autor de La vida es sueño procesaba el neoplatonismo que está también en la base de su gran comedia. Todo lo que tenga que ver con el sueño remite inevitablemente a Platón.

Hay en "Primero sueño" una saturación de terminología escolástica -potencias y facultades del alma, humores, vegetativa, etc.- que enfatiza el fracaso en alcanzar la verdad. Porque "Primero sueño" es un poema del fracaso, como siempre se ha sabido, pero del fracaso de un método y una filosofía, no del alma o del intelecto en sí. Toda esta saturación, que es lo menos moderno del poema, estructura el sueño de la razón. En ese desbordamiento escolástico Sor Juana está, en cierta medida, 
parodiando a Calderón y a todo un modo de pensar que se había convertido en la ideología de la cultura española de la época en sus manifestaciones más fundamentales e influyentes. La escolástica constituía el discurso de la verdad diseminado oficialmente inclusive en los claustros universitarios, al mismo tiempo que su escasa correspondencia con la realidad se hacía cada vez más palmaria y en algunos casos risible; esto es lo que explotó ese otro notable poeta virreinal que fue Juan del Valle y Caviedes en su burla de los médicos que, con sus obsoletos conocimientos, mataban a sus pacientes. Es también la causa de los retorcimientos retóricos, que a veces nos suenan cómicos, de Sigüenza y Góngora.

Subrayo. No es que la mente falle en su búsqueda de la verdad, es que el andamiaje escolástico que le permitía pensar se ha venido abajo. Este es el desengaño que se revela como tal en "Primero sueño", pero lo hace mientras está siendo usado a sabiendas de su falsedad. Esta es la esencia del barroco en Sor Juana: invalidar sistemas de conocimiento, activar discursos rebasados, periclitados, que dramatizan su inutilidad en el poema mismo. Repito y aclaro, la esencia del barroco en Sor Juana es su falta de esencia, el uso de discursos que se saben superados, incapaces de representar la verdad y de satisfacer el ansia de saber. Esto tiene significación histórica concreta. Sor Juana está demostrando la bancarrota ideológica del mundo virreinal; la dramatiza en su poema. Paz exagera la modernidad de Sor Juana, que él quiere aparejar a la suya (quiere hacer de ella una descreída existencialista). Hay un repliegue en Sor Juana, un poner a prueba el discurso escolástico que no es moderno y que, es, como ya dije lo que más nos choca hoy, tal vez lo menos poético para nosotros. Lo que sí hay es la prueba de su derrota. Hay en el trasfondo de todo esto mucho de Fray Luis de León, el mismo impulso por conocer, el mismo neoplatonismo de la "Noche serena" con sus estrellas fijas. Pero Fray Luis no abusa de la escolástica ni de la cosmología tolemaica, que está ahí en sus poemas como lo dado, como lo recibido para describir el espacio sideral. Sor Juana prefiere exprimirle el jugo a esos discursos para llevarlos al límite de su eficacia, aunque para ella no de su eficacia como poesía. Para la monja, la insuficiencia cognoscitiva de esos sistemas no cancela su capacidad para crear belleza, sólo que en "Primero sueño" es una belleza melancólica porque no va aliada a la verdad, como en las obras directamente derivadas del neoplatonismo; los poemas de Fray Luis, por ejemplo. Todo esto se nota en el empleo que hace la poeta del espacio, que es la base misma de la cosmología porque es en él que giran los planetas y se ubican las estrellas. El poema empieza precisamente con una sombra piramidal que se proyecta sobre la tierra, que a mí se me hace una suerte de eclipse.

El espacio es elemento fundamental en la temática de la arquitectura, que atraviesa todo "Primero sueño". La forma arquitectónica que más se destaca son las pirámides, que constituyeron un esfuerzo supremo por dotar al espacio de significado, de someterlo a límites significativos, o sea convertir el espacio en discurso, en "bárbaros jeroglíficos" (190), como escribe Sor Juana. La pirámide es 
una especie de arrebato vertical en que las líneas convergentes culminan en una síntesis sublime pero infructuosa en su ansia de llegar a Dios. En esto simulan el impulso ascendente del alma por lograr lo mismo. Las pirámides suponen un espacio infinito porque apuntan hacia él sin alcanzarlo, mientras que el sistema tolemaico supone un universo cerrado y completo -pensemos en la cuadratura rectangular de los edificios griegos y romanos-. De la misma manera el alma, sumida en un espacio infinito, no puede pensarse en su ser; no puede situarse. Sor Juana apoya todo el fracaso de la ideología escolástica vigente en su tiempo en los efectos de esa oposición. Ese espacio infinito es el que refleja el impacto de las nuevas teorías cosmológicas, que se han venido desarrollando a la zaga de la diseminación de Copérnico y Galileo a lo largo de los siglos XVI y XVII. Es algo que se puede percibir en Calderón, a pesar de su reputación de conformista promotor del pensamiento de la época, según veremos.

Sor Juana expresa en varios momentos de "Primero sueño" la perplejidad de la mente ante manifestaciones del infinito, que no puede abarcar y someter al conocimiento. Por ejemplo, cuando menciona el vuelo del alma en pos de la verdad primera:

La cual [el alma], en tanto toda convertida

a su inmaterial ser y esencia bella, aquella contemplaba, participada de alto Ser, centella que con similitud en sí gozaba; y juzgándose casi dividida de aquella que impedida siempre la tiene, corporal cadena, que grosera embaraza y torpe impide el vuelo intelectual con que ya mide la cuantidad inmensa de la Esfera, ya el curso considera regular, con que giran desiguales los cuerpos celestiales (culpa si grave, merecida pena torcedor del sosiego riguroso)..

Es decir, despojada el alma del peso del cuerpo que la lastra, y alcanzada por la chispa divina de Dios, observa el movimiento de los astros en la vasta esfera celeste, que ella ve como regulares pero son disparejos. Méndez Plancarte prosifica así este pasaje con suficiente fidelidad: "El Alma misma, entre tanto, reconcentrada toda ella en una como intuición de su propio ser espiritual y su esencia hermosa, contemplaba esa centella o chispa de Dios que goza dentro de sí, por participación en Él mismo le dio, al haberla creado a su semejanza. Juzgándose, además, casi desatada de la cadena del cuerpo, que la tiene siempre ligada, y que grosera y torpe 
le dificulta el vuelo intelectual con que ora mide la inmensidad del firmamento, ora estudia el armonioso y a la par variadísimo giro de las estrellas -especulación astronómica que, cuando degenera en la 'Astrología judiciaria', al querer vanamente predecir los futuros libres..." (25)-. Es decir, la interpretación astrológica del movimiento regular de los astros es culpable, en principio por no ser cristiana. Pero a mí lo que me interesa es que el infinito no permite el cabal cálculo del desplazamiento de los cuerpos celestes, aún en la ventajosa situación en que se encuentra el alma, aliviada del impedimento que constituye el cuerpo, y con éste los engañosos sentidos, en los que las teorías tolemaicas dependían. Méndez Plancarte lee en los versos finales de la cita una crítica de la astrología judiciaria, que estaría muy a tono con lo que ocurre en La vida es sueño, como se verá.

Más adelante, luego del intermezzo sobre las pirámides, y al ofrecer una definición de las mismas, Sor Juana alude a las líneas convergentes que aspiran a llegar a la Causa Primera, inalcanzable en el espacio infinito:

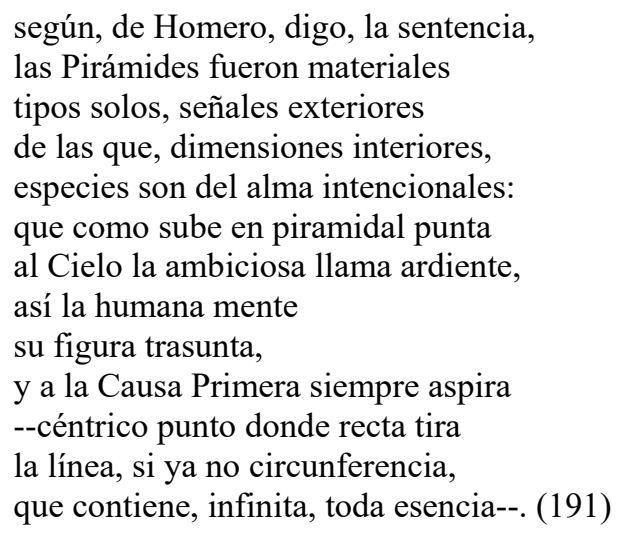

Méndez Plancarte traduce con relativa exactitud: "Según el aludido sentir de Homero, efectivamente, las Pirámides sólo fueron símbolos materiales, signos externos, de las dimensiones interiores que son especies intencionales del Alma, esto es, de la 'actitud del espíritu humano'-; pues como la ambiciosa llama ardiente sube al Cielo en punta piramidal, así el Alma trasunta esa figura, y siempre aspira a la Causa Primera, que es el Centro al que tienden todas las líneas rectas (toda verdad y todo justo anhelo), y la Circunferencia infinita en Si contiene -virtual y eminentemente- todas las esencias" (33). "Especies intencionales", terminología escolástica, quiere decir, más bien, representaciones visibles del alma -las pirámides son representación del alma-. Sebastián de Covarrubias dice en su magnífico Tesoro: "Especies significan las cosas que particularmente se pueden ver, assi como dezimos que hombre es de la especie humana, caballo de la equina, el león de la leonina, porque cada especie de éstas se ve en qualquier particular que se contiene en ella" (553). La línea recta es infinita y representa más cabalmente que la 
circunferencia ese anhelo ascendente del alma. Pero lo significativo es esa alma perdida en el espacio infinito apuntando hacia arriba a un punto inalcanzable. "Causa Primera" es, por supuesto, jerga escolástica, derivada de Aristóteles, para significar el Primer Motor, Dios, o sea la verdad. Esta estrofa contiene en sí el meollo mismo del poema, su significado tanto como el complejo conflicto de discursos que lo componen.

Por haber sido tan importante Calderón para Sor Juana, paso a hacer algunos comentarios sobre La vida es sueño, que me parecen pertinentes a lo que pretendo decir sobre "Primero sueño", y que me permiten iniciar mi conclusión. Ya la crítica ha mencionado la relación entre el poema y la comedia, que por los títulos mismos se hace casi inevitable, pero yo le doy un sesgo a la cuestión que se me antoja nuevo y distinto de lo dicho por Paz, por ejemplo, que tenía una visión demasiado convencional de la obra del dramaturgo madrileño. El conflicto sobre el conocimiento que atraviesa el poema de Sor Juana es el mismo que se solventa en la comedia de Calderón; la voz poética del poema la anticipa la del rey Basilio en $L a$ vida es sueño.

La comedia gira en torno a los errores de Basilio, cuya trayectoria tiene visos trágicos, sin llegar a ser tragedia porque al final Segismundo lo perdona. Los errores del rey son resultado de su desacertada interpretación astrológica de los sucesos, que se basa en teorías obsoletas del cosmos provenientes de Tolomeo, familiares para el público de la época, pero que Calderón tenía que saber ya no eran las vigentes como ciencia. Basilio no es sólo un monarca decrépito a punto de ceder el trono a un sucesor sino también un astrólogo atrasado, que aplica doctrinas tan anticuadas como él mismo. Felipe Picatoste asegura, en el que sigue siendo el mejor estudio de la filosofía del dramaturgo, que Calderón tenía que conocer las ideas de Copérnico aun cuando en sus comedias los personajes se expresaran en términos tolemaicos: "tenemos seguridad de que Calderón conocía el sistema copernicano; y es lo más probable que se expresara en estos términos [tolemaicos] para seguir la costumbre, sometiéndose al imperio de los sentidos"5. Calderón debía estar al tanto de la nueva cosmografía, conocida en la Península desde el siglo XVI, y estudiada en Salamanca, amén de que el propio Galileo quiso pasar algún tiempo en España. La vida es sueño se hace eco de las disyuntivas que estas nuevas y revolucionarias ideas crearon, como más tarde lo haría Sor Juana, sobre todo el concepto derivado de éstas sobre la infinitud del universo y la existencia de nuevos, tal vez innumerables planetas, algunos con satélites propios como descubrió Galileo con su telescopio en vida de Calderón. Sumido en esas incertidumbres se halla Basilio, angustiado por el anhelo de conocer los secretos del cosmos, pero armado con las superadas ideas tolemaicas. Sus desasosiegos son tal vez reflejo de los del propio

${ }^{5}$ Cito por la versión que incluimos Manuel Durán y yo en Calderón ante la crítica. Historia y antología, Madrid, Gredos, 1976, vol. II, p. 205. 
Calderón, que, de ser lo que propongo cierto, practicaba una "doble verdad," la de la iglesia y el vulgo por un lado, y la de las nuevas ideas por el otro, como propuso Américo Castro hizo Cervantes.

Basilio es un personaje fáustico que quiere no sólo descubrir los secretos del universo sino aprovecharse de ellos para ganarle la partida nada menos que al tiempo: "le gano al tiempo las gracias/de contar lo que yo he dicho" (622-23). Sus angustias son modernas, si bien, y he aquí el drama, sus métodos para enfrentarse a ellas son anticuados. Lo moderno es su reacción ante el sentido de su insuficiencia frente a la infinitud del tiempo, que tiene su contrapartida en el espacio estelar que observa -la nueva cosmografía pone de manifiesto la pequeñez de la tierra, no ya del hombre, en medio de la inmensidad sideral-. Lo anticuado son sus conocimientos de cosmografía y su insistencia en la posibilidad de leer el destino en los astros basándose en estos. Hay en Basilio no poca soberbia trágica. Dice que "por mi ciencia he merecido/el sobrenombre de docto" $(606-07,23)$ y "en el ámbito del orbe/me aclaman el gran Basilio" (610-11, 23). Nada menos. En La vida es sueño se demuestra que la cosmología tolemaica tiene la validez ficticia de la mitología clásica: está hecha de una serie previsible de alegorías que acoplan signo y significado ignorando el movimiento de ambos, la fluidez de su relación. Ahora no hay estrellas fijas. Todo esto desvirtúa cualquier interpretación de La vida es sueño que, siguiendo a Basilio, se base en la estabilidad de significados avalados por la astrología de origen tolemaico y la mitología ${ }^{6}$. En esto estriba la modernidad de La vida es sueño, que propone la necesidad de elaborar un nuevo método de lectura, ya que el antiguo queda asociado a la figura del rey vencido.

Las teorías tolemaicas son propias del Renacimiento, y las secuelas de las de Copérnico, con su nuevo énfasis en el infinito, pertenecen al Barroco. Tolomeo fue "redescubierto" como parte del rescate de los clásicos llevado a cabo por el humanismo. Su obra fue editada y comentada como la de éstos, además de impresa y diseminada. Era un sabio helenista cuyas ideas estaban en consonancia con las de los otros autores clásicos, griegos y romanos, ya sea porque, en el caso de los últimos conocían su obra, o porque, en el de los primeros coincidía con la de éstos, que fueron sus precursores; además todo se basaba en observaciones a ojo, de la bóveda celeste, sin la asistencia de avances matemáticos que no llegarían sino hasta mucho después, ni de aparatos ópticos de observación como el telescopio. Por una de esas ironías de la historia, en el momento cuando Tolomeo alcanza su mayor fama y reconocimiento, surge Copérnico, que echa abajo todo su sistema, aunque

6 Sabemos desde el importante libro de Jean Seznec, que los dioses antiguos sobrevivieron el advenimiento del cristianismo, que se fueron adaptando a su desarrollo, pero ya no con validez religiosa, sino como alegorías y catálogos de ejemplos. La nueva cosmografía los relegó a una nomenclatura para seguir nombrando los fenómenos de un cielo que ya no es el paradisíaco. 
este último protestaba que no era esa su intención; para no hablar, poco después de la aparición de Galileo, con artefactos que le daban confirmación visual a las nuevas teorías. En el barroco Tolomeo y su bello pero caduco sistema continúa vigente como código artístico para describir y denominar el universo, pero vulnerado por el conocimiento de su invalidez. Esto provocó a veces debates tardíos, como el mencionado sobre los cometas, o poemas, como "Primero sueño" que dramatizan su anulación.

Hay una relación causa-efecto entre la derrota de Basilio, es decir, el colapso de la autoridad recibida y la dramatización de los resultados del vaciamiento de códigos como la mitología y la cosmografía tolemaica. El Barroco es una danza de dioses cascados, una coreografía cuyo guion ahora lo da la improvisación que, por su misma naturaleza, prescinde de lo que le precede para montar su propio arreglo sobre la falla de lo desaparecido, como en el caso de Segismundo, que se improvisa rey dos veces, la segunda asistido por la experiencia de la primera, no por la herencia que Basilio le ha dejado. Ese baile es fastuoso, exagerado, en proporción inversa a su propia afectada insustancialidad que manifiesta su condición frágil, temporal, nula ante el fondo infinito contra el que se ejecuta. Lo fundamental del barroco es que se siguen usando códigos que ya se saben vencidos.

He propuesto cuatro ideas sobre "Primero sueño". La primera es que la presencia del infinito que la nueva cosmología post-copernicana trae consigo, determina la insuficiencia del alma en busca de conocimiento y, en última instancia, de Dios. La segunda es que en el poema se pone en práctica la técnica barroca de utilizar discursos que se saben superados, especialmente toda una terminología de origen escolástico que satura el poema y cuya proliferación aumenta en relación inversa a su falta de validez. Derivada de ésta, a un nivel teórico, he sugerido que la equivalencia entre signo y significado sobreentendida en la nomenclatura tolemaica se pone en jaque. La tercera es que en el poema la voz de Sor Juana no se identifica con el individuo que sueña sino hasta el final, de forma sorpresiva, porque media entre ella y su interior un discurso que le es ajeno, y que la aleja de sí. Por último, la cuarta, es que la derrota que dramatiza "Primero sueño" anuncia y proclama la decadencia del andamiaje político y cultural del virreinato, la bancarrota de su discurso.

\section{BIBLIOGRAFÍA}

ARDONO, Rolena.

2015 "El México antiguo en el Barroco de Indias: don Carlos de Sigüenza y Góngora", Anales de Estudios Latinoamericanos (Asociación Japonesa de Estudios Latinoamericanos, Tokio) 35, pp. $1-42$. 
2014 "Carlos de Sigüenza y Góngora (1645-1700):'el amante más fino de nuestra patria”, Hispanófila 171 (junio 2014), pp. 11-27.

GONZÁLEZ ECHEVARRÍA, Roberto.

1993 Celestina's Brood: Continuities of the Baroque in Spanish and Latin American Literatures. Durham: Duke University Press.

1999 La prole de Celestina: continuidades del barroco en las literaturas española e hispanoamericana. Madrid: Editorial Colibrí.

2006 "Lírica colonial", en Historia de la literatura hispanoamericana: Cambridge. Madrid: Gredos, pp. 215-251.

2014 "Infinito e improvisación en La vida es sueño", en Bulletin of the Comediantes 66, $\mathrm{n}^{\mathrm{o}} 2$ (2014), pp. 141-160.

GARCÍA SANTO TOMÁs, Enrique.

2015 La musa refractada: literatura y óptica en la España del Barroco. Madrid: Iberoamericana-Vervuert.

JUANA INÉS DE LA CRUZ, Sor.

1951 El sueño, edición y prosificación e introducción y notas del Dr. Alfonso Méndez Plancarte. México: Imprenta Universitaria.

1977 Obras completas. Pról. de Francisco Monterde. México: Editorial Porrúa.

PicATOSTE, Felipe.

1976 "Concepto de la naturaleza deducido de las obras de don Pedro Calderón de la Barca", en Calderón ante la crítica. Historia y antología. Manuel Durán y Roberto González Echevarría (eds.). Madrid: Gredos, I, pp. 166-248.

PAZ, Octavio.

1983 Sor Juana Inés de la Cruz o las trampas de la fe. México: FCE.

SEZNEC, Jean.

1940 Survivance des dieux antiques; essai sur le rôle de la tradition mythologique dans l'humanisme et dans l'art de la Renaissance. Londres: Warburg Institute. 